\title{
Analgesic Effects of Intrathecally Administered Fentanyl in Spinal Anaesthesia for Lower Limb Surgery
}

Olanrewaju N. Akanmu ${ }^{1 *}$, Olaitan A. Soyannwo ${ }^{2}$, Patience T. Sotunmbi ${ }^{2}$, Adesuwa S. Lawani-Osunde ${ }^{1}$, Ibironke Desalu ${ }^{1}$, Oyebola O. Adekola ${ }^{1}$, Sofela E. Oridota ${ }^{3}$

${ }^{1}$ Department of Anaesthesia, College of Medicine, University of Lagos, Idi-Araba, Lagos, Nigeria; ${ }^{2}$ Department of Anaesthesia, University College Hospital, Ibadan, Oyo State, Nigeria; ${ }^{3}$ Department of Community Health and Primary Care, College of Medicine, University of Lagos, Idi-Araba, Lagos, Nigeria

\begin{abstract}
Citation: Akanmu ON, Soyannwo OA Sotunmbi PT, Lawani-Osunde AS, Desalu I, Adekola OO, Oridota SE. Analgesic Effects of Intrathecally Administered Fentanyl in Spinal Anaesthesia for Lower Limb Surgery. Maced Med Sci. 2013 Sep 15; 6(3):255-260. http://dx.doi.org/10.3889/MJMS.1857-5773.2013.0302 Key words: intrathecal; subarachnoid block; analgesia; fentanyl; complications.

"Correspondence: Olanrewaju N. Akanmu. Department of Anaesthesia, College of Medicine, University of Lagos, Idi-Araba, Lagos. Nigeria. E-mail: oakanmu@unilag.edu.ng, lanre.akanmu@yahoo.com

Received: 22-May-2013; Revised: 21-Jun2013; Accepted: 22-Jun-2013; Online first: 02-Sep-2013

Copyright: () 2013 Akanmu ON. This is an open-access article distributed under the terms of the Creative Commons Attribution License, which permits unrestricted use, distribution, and reproduction in any medium, provided the original author and source are credited.

Competing Interests: The authors have declared that no competing interests exist.
\end{abstract}

\begin{abstract}
Background: Intrathecal opioids as adjuvants to local anaesthetics during spinal anaesthesia have been used to augment the analgesia produced by local anaesthetic agents. The aim of this study is to determine the duration of analgesia following addition of fentanyl to $0.5 \%$ hyperbaric bupivacaine during open reduction of lower limb fractures.

Material and Methods: This prospective randomized study is comparing the effect of addition of $25 \mu \mathrm{g}$ of fentanyl to $10 \mathrm{mg}$ of $0.5 \%$ hyperbaric bupivacaine intrathecally on sixty consecutive ASA I and II patients scheduled to undergo elective open reduction and internal fixation of lower limb fractures (ORIF) at the $\mathrm{UCH}$, Ibadan. The patients were randomized into their either bupivacaine saline $(\mathrm{SB} \mathrm{n}=30) 10 \mathrm{mg}(2 \mathrm{ml}) \mathbf{0 . 5 \%}$ hyperbaric bupivacaine or bupivacaine-fentanyl combination ( $F B n=30$ ) through a 25-guage Whitacre spinal needle. Quality and duration of analgesia as well as any sequelae were recorded.
\end{abstract}

Result: Socio-demographic as well as operating data were comparable between the two groups. Fentanyl provided significantly longer duration of complete $(239.97 \pm 28.58$ vs $129.17 \pm 11.61)$, $p<0.001$ and effective $(276.23 \pm 26.21$ vs $150.80 \pm 10.33)$ analgesia than bupivacaine alone $(p<0.001)$. The pain intensity (visual analog scale [VAS]) at the time to first post-operative analgesic dose in the Fentanyl-Bupivacaine (FB) groups was significantly lower than in the group BS $(p<0.001)$. Eight of the patients in the control group BS $(26.67 \%)$ group had hypotension whereas six patients $(20 \%)$ in FB groups had hypotension that required rapid infusion of crystalloid. There was no statistical difference in the level of shivering in the two groups. No patient in either group developed respiratory insufficiency.

Conclusion: Addition of $25 \mu \mathrm{g}$ of fentanyl to $10 \mathrm{mg}$ of $0.5 \%$ hyperbaric bupivacaine intrathecally for open reduction and internal fixation of lower limb fractures significantly prolonged the duration of complete analgesia as well as effective analgesia thereby reducing the need for early postoperative analgesic use without increase in severe adverse effect.

\section{Introduction}

Postoperative pain after spinal anesthesia is a common complication in patients undergoing lower limb orthopedic surgeries. Neuraxial opioids are widely used in conjunction with local anesthetics (LAs) as they permit the use of lower dose of local anesthetics, while providing adequate anesthesia and analgesia [1, 2]. Neuraxial opioids also allow prolonged analgesia in the postoperative period and faster recovery from spinal anesthesia [3, 4]. The use of opioids in conjunction with local anesthetic for spinal anesthesia has been associated with decreased pain scores and reduced analgesic requirement in the post-operative period [5-7]. Neuraxial administration of opioids along with local anaesthetics has gained popularity in lower extremities surgeries due to these advantages [8-10]. 
The profound segmental antinociception produced by neuraxial opioids in doses much smaller than would be required for comparable antinociception if administered systemically has made them very popular and effective in the treatment of many painful states. They improve the quality of intraoperative anesthesia, permit lower doses of local anaesthetics, provide faster onset of surgical block and prolong the duration of postoperative analgesia [10].

The antinociception is also devoid of motor, sensory and autonomic blockade so there is no paralysis or hypotension [11]. Furthermore, the availability of a specific opioid receptor antagonist naloxone to reverse their action when necessary has made the use of opioids more acceptable. In addition to intraoperative analgesia, effective post-operative pain control is crucial in the postoperative recovery of orthopaedic patients as it encourages early mobilization, recovery and rehabilitation.

Fentanyl is a synthetic lipophilic opioid with a rapid onset of action and unlike morphine, has fewer tendencies to migrate rostrally to the fourth ventricle in sufficient concentration to cause delayed respiratory depression [12]. Neuraxial administration of other opioids such as sufentanil and meperidine with local anaesthetics (LAs) has also been demonstrated to prolong early postoperative analgesia compared with the use of local anaesthetic agents alone [12-14].

Side effects linked to intrathecal opioid administration like pruritus, PONV, urinary retention and respiratory depression might retard their use in certain population of patients $[11,15,16]$. In our country; Nigeria sustained opioid availability is a major challenge in the management of patients with perioperative pain as a result of trauma and other painful states [17] hence there is paucity of knowledge on the usefulness or otherwise of intrathecal fentanyl. The aim of our study was to evaluate the duration of analgesia and other clinical effects of 25 microgram $(\mu \mathrm{g})$ subarachnoid fentanyl added to hyperbaric bupivacaine compared with hyperbaric bupivacaine and saline in patients having open reduction and internal fixation (ORIF) of lower limb fractures

\section{Materials and Methods}

Following ethical approval the joint University College Hospital Ibadan/University of Ibadan, Ethics Committee, written and verbal consent was obtained from all study participants before being recruited. Sixty (60) healthy adults of American Society of Anaesthesiologist (ASA) physical status 1 patient aged 17 to 85 years were randomized into two groups using table of random numbers method into group SB (control group) and group FB (study group). The control group had $2.0 \mathrm{ml}$ of $0.5 \%$ hyperbaric bupivacaine with $0.5 \mathrm{ml}$ of saline to make up to $2.5 \mathrm{ml}$ while the study group had $2.0 \mathrm{ml}$ of $0.5 \%$ hyperbaric bupivacaine plus $25 \mu \mathrm{g}$ of fentanyl $(0.5 \mathrm{ml})$ making up to $2.5 \mathrm{ml}$. The study drug was prepared by one of the investigators who was not involved with perioperative management of the patients.

\section{Exclusion criteria included; Patients in whom} spinal anesthesia or the study drugs are contraindicated. Patients with neurological disease, spinal deformities, local skin infection or mental disorders; those who were morbidly obese, hemodynamically unstable or having coagulation disorders, or patients with liver disease, impaired renal functions, ASA Physical status $>2$ or a history of opioid dependence were also excluded from the study. Any medical condition precluding the use of spinal anaesthesia and refusal. Each patient was taught how to use the Visual Analog Scale (VAS); graded $1-100 \mathrm{~mm}$, from $0=$ no pain to $100=$ worst pain imaginable pre-operatively and was fasted overnight. Premedication was omitted.

All patients were preloaded with crystalloids (Lactated Ringer's solution) at $15 \mathrm{ml}$ per kilogram body weight $15 \mathrm{~min}$ before induction of anaesthesia through 16G peripheral IV cannula. Base line haemodynamic parameters were documented using standard multiparameter monitor. The pulse rate oxygen saturation, systolic blood pressure and diastolic blood pressure were monitored.

The subarachnoid block was instituted under strict aseptic condition with patients in the sitting position. The puncture site was at L3-L4 vertebral after the skin and interspinous ligament were infiltrated with $2 \mathrm{ml}$ of $1 \%$ plain lidocaine. $10 \mathrm{mg}(2 \mathrm{ml})$ of $0.5 \%$ hyperbaric bupivacaine with $0.5 \mathrm{ml}$ of saline or $10 \mathrm{mg}(2 \mathrm{ml})$ of $0.5 \%$ hyperbaric bupivacaine with $25 \mu \mathrm{g}$ of fentanyl $(0.5 \mathrm{ml})$ was injected for group SB and group FB respectively. After the spinal injection, each patient was placed supine with a pillow to support the head and the shoulders. The end of spinal injection was taken as time 0 . Oxygen at 2-3 L/min was administered via a facemask or intranasal catheter. Observation and assessment of the block with the evaluation of the patients were charted by a blinded anaesthesist.

Patient blood pressure (measured by automated non-invasive blood pressure monitor), heart rate, respiratory rate, and $\mathrm{SaO}_{2}$ (measured by pulse oximeter) were recorded at intervals of 2 minutes for the first ten minutes, and thereafter at 5 minute intervals. The height of the block was tested along the mid-axillary line and the outer aspect of the thigh at $3,5,10$ and 15 minutes using response to pinprick. Motor block was assessed along with the sensory block, using the Bromage scale $(0=$ full movement of hip, knee and ankle; 1=ability to flex knees but no hip movement; 2=unable to flex knees, but no problems with ankle movement; $3=$ no movement possible with any of the lower extremity joints). Intraoperative discomfort with the following scores [0 no distress; 1 slight distress -needing a single dose of anxiolysis; 2 moderate distress needing two doses; 3 intense distress - needing more 
than two doses]

Adverse events such as hypotension, bradycardia, nausea, vomiting, pruritus, patient discomfort, shivering and respiratory depression were monitored and documented and specific treatment modalities given as per standard protocol.

Systolic blood pressure of below $90 \mathrm{mmHg}$ or lower than $30 \%$ of starting systolic blood pressure was considered as hypotension and was treated with intravenous crystalloids with or without ephedrine. Heart rate less than 60 beats/minutes was considered as bradycardia and treated with $0.5 \mathrm{mg}$ of atropine while pruritus and respiratory depression i.e. respiratory rate less than 10 breaths per minute and oxygen saturation less than $90 \%$ was treated with Intravenous Naloxone. Report of discomfort during surgery was also documented.

In the recovery room and on the ward, the patients were monitored by nursing staff who had earlier been trained on how to use the Visual Analog Scale (VAS). Monitoring included respiratory rate, oxygen saturation and the pain intensity score every fifteen minutes for the first one hour and thereafter every thirty minutes postoperatively.

Parenteral pentazocine at a dose of $1 \mathrm{mg} / \mathrm{kg}$ was administered intramuscularly at patient's first request for analgesia or when pain intensity assessment using the VAS was $\geq 40.00 \mathrm{~mm}$. The duration of complete analgesia was taken as time from the intrathecal injection to the time of first request for analgesia.

\section{Data analysis}

The null hypothesis $\left[\mathrm{H}_{\mathrm{O}}\right]$, that there is no difference in the duration of analigesia following addition of $25 \mu \mathrm{g}$ of fentanyl intrathecally to $10 \mathrm{mg}$ of $0.5 \%$ hyberbaric bupivacaine with saline in patients undergoing ORIF for lower limb fractures was tested. The Alternate Hypothesis $\left[\mathrm{H}_{\mathrm{A}}\right]$ which states that addition of $25 \mu \mathrm{gg}$ of fentanyl to $10 \mathrm{mg}$ of $0.5 \%$ hyperbaric bupivacaine intrathecally provide a longer duration of analgesia than the use of $10 \mathrm{mg}$ of $0.5 \%$ hyperbaric bupivacaine with saline in patients undergoing ORIF for lower limb fractures was equally tested. The significant $p$-value was corrected with a $p$ value of 0.05 .

Data obtained were entered into SPSS $^{\mathrm{R}}$ package (statistical package for social sciences) version 17 and analysed. Data were analysed by using unpaired 't' test $p$-value $<0.05$ was considered statistically signifcant. Data are presented as mean values \pm Standard deviation (SD) and numbers (percent).

\section{Results}

The two study groups were comparable with respect to demographic characteristics as evidence by the means and standard deviations of demographic characteristics presented in Table 1. There were no statistically significant differences in the ages, weight, height, and the durations of surgery in the two study groups.

Table 1: Demographic characteristics. Values presented as numbers, mean \pm SD.

\begin{tabular}{lll}
\hline & Group SB (Control & Group FB (Study \\
& Group) [n=30] & Group) [n=30] \\
\hline Age[yrs] & $43.23 \pm 12.60$ & $42.03 \pm 12.61$ \\
Weight [kg] & $66.77 \pm 8.54$ & $72.60 \pm 10.82$ \\
Height [m] & $1.68 \pm 0.04$ & $1.68 \pm 0.04$ \\
Duration of surgery [min] & $106.53 \pm 5.59$ & $104.67 \pm 5.30$ \\
\hline
\end{tabular}

The highest sensory level achieved was T3 (T3-T6) andT4 (T4-T6) in group SB and group FB respectively. The time from injection of the test drugs to achievement of the highest sensory level was similar in both groups, $7.40( \pm 0.82)$ minutes and 7.37 $( \pm 0.83)$ for Group SB and FB respectively with a $p$ value of 0.876 . Time of onset of grade 3 motor blockade using Bromage scale was also similar in both groups i.e. $5.98( \pm 0.74)$ minutes in group SB and $5.42( \pm 0.51)$ minutes.

Table 2: Sensory and Motor block. Results presented as Mean \pm Standard deviation.

\begin{tabular}{lll}
\hline & $\begin{array}{l}\text { Group SB } \\
\text { (Control Group) }\end{array}$ & $\begin{array}{l}\text { Group FB } \\
\text { (Study Group) }\end{array}$ \\
\hline $\begin{array}{l}\text { Highest Sensory Level } \\
\text { (range) }\end{array}$ & $\mathrm{T}_{3}\left(\mathrm{~T}_{3}-\mathrm{T}_{6}\right)$ & $\mathrm{T}_{4}\left(\mathrm{~T}_{4}-\mathrm{T}_{6}\right)$ \\
$\begin{array}{l}\text { Time from injection to } \\
\text { highest sensory level (min) }\end{array}$ & $7.40 \pm 0.82$ & $7.37 \pm 0.83$ \\
$\begin{array}{l}\text { Time of onset of grade 3 } \\
\text { motor block (min) }\end{array}$ & $5.98 \pm 0.82$ & $5.42 \pm 0.51$ \\
\hline
\end{tabular}

Time of complete analgesia (the time from injection of intrathecal drugs to the time of first complaint of pain by the patient) in Group FB was significantly longer than the group SB with a mean \pm standard deviation of $239.97 \pm 28.58$ minutes compared to $129.17 \pm 11.61$ and $p$-value of $<0.001$.

Table 3 shows that the time of effective analgesia (i.e. the time from injection of intrathecal drugs to the time for request for analgesia) was significantly longer in the group FB compared to group $\mathrm{SB}, 276.23 \pm 26.21$ and $150.80 \pm 10.33$ minutes respectively as the $p$-value was $<0.001$. Pain intensity at this period was significantly lower in the FB group $(p<0.001)$ as evaluated by VAS.

The commonest side effect observed intraoperatively was shivering as shown in Table 4 with ten patients $(33.33 \%)$ in Group SB compared to seven patients $(23.33 \%)$ in group FB. Treatment included application of more drapes and blanket to keep patient warm and reassurance by the 
anaesthesists, none needed pharmacological intervention.

Table 3: Duration of analgesia/Pain intensity at the time of analgesia request. Results presented as mean \pm SD.

\begin{tabular}{llll}
\hline & Group SB & Group FB & p-value \\
\hline $\begin{array}{l}\text { Time of complete analgesia } \\
\text { (minutes) }\end{array}$ & $129.17 \pm 11.61$ & $239.97 \pm 28.58$ & $<0.001$ \\
$\begin{array}{l}\text { Time of effective analgesia } \\
\text { (minutes) }\end{array}$ & $150.80 \pm 10.33$ & $276.23 \quad \pm \quad<0.001$ \\
Visual analogue scale $(\mathrm{mm})$ & $66.50 \pm 4.01$ & 26.21 & \\
\hline
\end{tabular}

Nausea was reported in six $(20.00 \%)$ patients in Group SB compared to four (13.24\%) patient in Group FB. The development of nausea preceded the onset of hypotension in five patients that had hypotension (four in group SB and one in group FB). However none of patients in either group vomited. Six patients $(20 \%)$ in Group SB complained of discomfort intraoperatively while two $(6.67 \%)$ was reported in Group FB. All the patients were reassured by the anaesthetists and none had intravenous pharmacological treatment. Pruritus was more prevalent $(6.67 \%)$ in the FB group, it was however not observed intraoperatively and for the duration of the study in the other group (SB). There was no incidence respiratory depression (Respiratory rate $<10$ breaths per minute) or of adverse desaturation in both groups.

Table 4: Incidence of Perioperative adverse effects. Results presented as numbers (percentage).

\begin{tabular}{lcc}
\hline & $\begin{array}{c}\text { Group SB } \\
\text { (Control) } \mathrm{n}(\%)\end{array}$ & $\begin{array}{c}\text { Group FB } \\
(\text { Study) } \mathrm{n}(\%)\end{array}$ \\
\hline $\begin{array}{l}\text { Hypotension (fall of systolic BP>30\% } \\
\text { from baseline level or systolic BP }<\end{array}$ & $8(26.67 \%)$ & $6(20 \%)$ \\
$90 \mathrm{mmHg})$ & & \\
Bradycardia (HR<60 min) & $5(16.67 \%)$ & $2(6.67 \%)$ \\
Nausea & $6(20.00 \%)$ & $4(13.24 \%)$ \\
Vomiting & 0 & 0 \\
Pruritus & 0 & $2(6.67 \%)$ \\
Respiratory depression & 0 & 0 \\
Shivering & $10(33.33)$ & $7(23.33 \%)$ \\
Patient discomfort & $6(20 \%)$ & $2(6.67 \%)$ \\
Sedation & 0 & 0 \\
\hline
\end{tabular}

Bradycardia (HR<60min) occurred in five patients $(16.67 \%$ ) in Group SB. Hypotension (fall of systolic $\mathrm{BP}>30 \%$ from base level or systolic $\mathrm{BP}<90$ $\mathrm{mmHg}$ ) was seen in eight $(26.67 \%)$ patients in Group SB while six $(20 \%)$ of the patients in FB group had hypotension. All the patients who had hypotension were promptly treated with rapid infusion of crystalloid and none needed the use of vasopressors. The five patients who had bradycardia in group SB also develop hypotension two of them had a sensory level of $\mathrm{T}_{3}$. The bradycardia was treated with a bolus dose of IV $0.5 \mathrm{mg}$ of Atropine with good effect.

\section{Discussion}

In the last decade, spinal anaesthesia became the commonest anaesthesia technique used for lower extremity surgery [18]. The patient is able to communicate with the Health Care Workers (HCWs) during the surgery and the method is safer than general anaesthesia because it is well tolerated, produces less postoperative confusion and delirium than general anaesthesia in the patient [19].

\section{Subarachnoid hyperbaric bupivacaine} produce high sensory blockade reaching T4-T6 may be insufficient and additional intraoperative analgesia may be required [20]. Higher doses of bupivacaine increases the level of blockade, are likely to enhance hypotension, induce breathing difficulties and neurotoxicity [20, 21]. In order to limit their adverse effects, local anaesthetic agents are combined with low doses of opioids. Administered subarachnoidly, they improve the quality of intraoperative analgesia and their analgesic effects last into the postoperative period $[3,8]$.

In this study, the mean (SD) duration of complete analgesia (time from injection of intrathecal drug to when patient complained of pain i.e. when pain score is $>0$ ) in the bupivacaine with saline group (group SB) was 129.17 minutes $( \pm 11.61)$, however with the addition of $25 \mu \mathrm{g}$ fentanyl (group FB); the duration of analgesia increase significantly to 239.46 minutes ( \pm 28.58). Similarly the duration of effective analgesia (time from injection of intrathecal drug to time of request for analgesic) also significantly increased $(p<0.001)$. Studies $[22,23]$ on animal suggested a synergism between opioids and local anaesthetic agents, they showed specific enhancement by opioids on the effects of intrathecal local anaesthetic agent on nociceptive afferent but not on sympathetic efferent pathways. The result of our study was similar to that of Biswas et al [24] who reported improved duration and quality of analgesia in the early postoperative period following addition of $12.5 \mu \mathrm{g}$ of fentanyl to $10 \mathrm{mg}$ of bupivacaine with mean (SD) duration of complete analgesia of 189 minutes $( \pm$ 9) compared with 129 minutes $( \pm 9.5)$ in the bupivacaine only group in obstetrics patients. In the same study they reported a statistically significant difference in the mean duration of effective analgesia of 248 minutes in the fentanyl with bupivacaine group and 150 minutes in the bupivacaine only group

Similarly Belzarena [25] compared clinical effects of bupivacaine with saline and bupivacaine with various doses of intrathecally administered fentanyl in patients undergoing Caesarean section. He reported that effective postoperative analgesia lasted longer and significantly increased with increasing doses of fentanyl administered. In the study the mean duration of analgesia was 197 minutes in group $\mathrm{O}$ (bupivacaine only), group 25 (addition of $0.25 \mu \mathrm{g} / \mathrm{kg}$ of fentanyl) was 305 minutes; group 50 (addition of 0.50 $\mu \mathrm{g} / \mathrm{kg}$ fentanyl) was 640 minutes and group 75 (addition of $0.75 \mu \mathrm{g} / \mathrm{kg}$ of fentanyl) was 787 minutes. However complications such as pruritus, sedation and respiratory depression increased with increasing doses of fentanyl. He also noted that the time to request of postoperative analgesic increased while total analgesic consumption decreased in dose dependent manner. Khanna et al [26] showed that the 
time of the first patient request for analgesia (TAR i.e effective analgesia) following addition of $25 \mu \mathrm{g}$ of fentanyl to $0.5 \%$ bupivacaine for orthopaedic patient undergoing hip replacement was 219.6 minutes. Our findings of non affectation of onset of sensory or motor block but prolonged duration of sensory block without prolongation of recovery of motor block agree with those of previous studies $[6,9,25-28]$ that reported similar finding

Dahlgreen and coworkers [13] compared the effects of intrathecal sufentanil $2.5 \mu \mathrm{g}$ and $5 \mu \mathrm{g}$, fentanyl $10 \mu \mathrm{g}$ and placebo when administered together with $12.5 \mathrm{mg}$ of $0.5 \%$ hyperbaric bupivacaine in a randomized double blind study and noted that the duration of complete analgesia (defined as the time from intrathecal injection to VAS $>0$ ), was prolonged in all groups receiving opioids. Patients who had $5 \mu \mathrm{g}$ of sufentanil had significantly longer duration of analgesia than those who had $10 \mu \mathrm{g}$ fentanyl. Yu et al in their study [14] showed that there was a significant difference in the effective duration of analgesia (defined as the time of intrathecal injection to the first patient controlled analgesia demand), following addition of $10 \mathrm{mg}$ pethidine to $2.0 \mathrm{ml}$ of $0.5 \%$ hyperbaric bupivacaine (mean 234 minutes) compared with the addition of saline (mean 125 minutes) which was also the same in our study.

It is particularly important to note that there were no statistically significant differences in the incidence of side effects such as hypotension, bradycardia, nausea, vomiting, shivering, respiratory depression or patient discomfort as seen in Table 4. There was no significant effect of addition of $25 \mu \mathrm{g}$ of fentanyl. The lack of respiratory depression observed in our study was similar to the finding by Varrassi et al [29] that $25 \mu \mathrm{g}$ of intrathecal fentanyl during spinal anaesthesia did not alter respiratory rate, minute ventilation, EtCO2, respiratory drive, timing or the ventilator response to $\mathrm{CO} 2$ in their patients

The subarachnoid block induced comparable decrease in blood pressure inspite of preloading with $15 \mathrm{ml} / \mathrm{kg}$ of lactated Ringer's in the two groups. This is similar to finding of previous study [30] that reported that preloading does not regularly preclude hypotension induced by sympathectomy during spinal anaesthesia. Our study also show that intrathecal fentanyl does not alter cardiovascular response to subarachnoid anaesthesia.

Similarly the fentanyl (FB) group besides having prolonged duration of sensory block/effective analgesia had lower VAS scores than the control (BS) group $p<0.001$ (Table 3 ). This is possibly due to the residual analgesic effect of the fentanyl that became manifest after the sensory block due to the effect of the intrathecal local anaesthetic $(0.5 \%$ hyperbaric bupivacaine) had been dissipated.

The results from this study showed that addition of $25 \mu \mathrm{g}$ of fentanyl to $10 \mathrm{mg}$ of $0.5 \%$ hyperbaric bupivacaine intrathecally for open reduction and internal fixation of lower limb fractures significantly prolonged the duration of complete analgesia as well as effective analgesia thereby reducing the need for early postoperative analgesic use.

\section{References}

1. Hindle A. Intrathecal opioids in the management of acute postoperative pain. Continuing Education in Anaesthesia, Critical Care \& Pain. 2008; 8: 81-85.

2. Stocks GM, Hallworth SP, Fernando R, England AJ, Columb MO, Lyons G. Minimum local analgesic dose of intrathecal bupivacaine in labour and the effect of intrathecal fentanyl. Anesthesiology. 2001; 94: 593-598.

3. Kuusniemi KS, Pihlajamaki KK, Pitkanen MT, Helenius HY, Kirvela OA. The use of bupivacaine and fentanyl for spinal anesthesia for urologic surgery. Anesth Analg. 2000; 91: 14521456.

4. Dayioglu H, Baykara ZN, Salbes A, Solak M, Toker K. Effects of adding magnesium to bupivacaine and fentanyl for spinal anaesthesia in knee arthroscopy. J Anesth. 2009; 23: 19-25.

5. Wojciech W, Andrzej B, Sietlana K-W, Ewa M-Z. Comparative study of postoperative analgesia after intrathecal administration of bupivacaine with fentanyl or morphine for elective caesarean section. Anaesthesiol Intensive Ther. 2009; 1:25-29.

6. Ben-David B, Solomon E, Levin H, Admoni H, Gold Z. Intrathecal fentanyl with small dose dilute bupivacaine: Better anesthesia without prolonging recovery. Anesth Analg. 1997; 85: $560-565$.

7. Demiraman Y, Yucell AK, Cali GE, Degirmenci E, Sezen G, Iskender A. Adding intrathecal morphine to unilateral spinal anesthesia results in better pain relief following knee arthroscopy. J Anesth. 2008; 22: 367-72.

8. Abouleish E, Rawal N, Shaw J, Lorenz T and Rashad MN. Intrathecal morphine $0.2 \mathrm{mg}$ versus epidural bupivacaine $0.125 \%$ or their combination; effects on parturients. Anesthesiology. 1991; 711-716.

9. Khezri MB, Yaghobi S, Hajikhani M, Asefzadeh S. Comparison of postoperative analgesic effect of intrathecal magnesium and fentanyl added to bupivacaine in patients undergoing lower limb orthopedic surgery. Acta Anaesthesiol Taiwan. 2012; 50(1):19-24.

10. Hunt CO, Naulty JS, Bader AM. Perioperative analgesia with subarachnoid fentanyl with bupivacaine for Caesarian delivery. Anesthesiology. 1989; 71; 535-540.

11. Morgan $M$. The rational use of intrathecal and extradural opioids. Br J Anaesth. 1989; 63: 165-188.

12. Etches RC, Sandler AN, Daley MD. Respiratory depression and spinal opioids. Can J Anaesth. 1989; 71; 165-185.

13. Dahlgreen G, Hultstrand C, Jakobsson J, Norman M, Eriksson EW, Martin H. Intrathecal sufentanil, fentanyl or placebo added to bupivacaine for Caesarian section. Anesth Analg. 1997; 85: 1288-1293.

14. Yu SC, Kee Ngan WD, Kwan ASK. Addition of meperidine to bupivacaine for spinal anaesthesia for Caesarean section. $\mathrm{Br}$ J. Anaesth. 2002; 88: 379-383.

15. Shadangi BK, Garg R, Pandey R, Das T. Effects of intrathecal midazolam in spinal anaesthesia: a prospective randomized case control study. Singapore Med J. 2011; 52(6): 432-435.

16. Nanjegowda N, Nataraj MS, Kavaraganahalli DM, Kini G. The effects of intrathecal midazolam on the duration of analgesia in patients undergoing knee arthroscopy. South Afr J Anaesth Analg. 2011; 17(3): 255-259.

17. Soyannwo OA. Post-operative pain control prescription pattern 
and patients' experience. West Afr. J Med. 1999; 18: 207-210.

18. Siegel T and Mayzner-Zawadzka E. Regionalna anestezja w Polsce w 2002 roku. Anaesthesiol Intensive Ther. 2004; 36: 89-96.

19. Chung F, Seyone $C$, Dyck $B$ et al. age related cognitive recovery after general anaesthesia. Anaesth Analg. 1990; 71: 217-24.

20. Duck HC, Hyun JA, Myung HK. Bupivacaine sparing effect of fentanyl in spinal anaesthesia in elective caesarean delivery. Reg Anesth Pain Med. 2000; 25: 240-245.

21. Hodgson PS, Neal JM, Pollock JE, Liu SS. The neurotoxicity of drugs given intrathecally. Anesth Analg. 1999; 88: 797-809.

22. Maves TJ, Gebhart GF. Antinociceptive surgery between intrathecal morphine and lidocaine during visceral and somatic nociception in the rat. Anesthesiology. 1992; 76: 91-99.

23. Wang C, Chakrabarti MK, Whitwam JG. Specific enhancement by fentanyl on the effects of intrathecal bupivacaine on nociceptive afferent but not on sympathetic efferent pathway in dogs. Anesthesiology. 1993; 79: 766-773.

24. Biswas BN, Rudra A, Bose BK, Nath S, Chakrabaty S, Bhattacharjee S. Intrathecal fentanyl with hyperbaric bupivacaine improves analgesia during caesarean delivery and in the early post-operative period. Indian J Anaesth. 2002; 46: 469-472.

25. Belzarena S. Clinical effects of intrathecally administered fentanyl in patients undergoing Caesarean section. Anesth Analg. 1992; 74: 653-657.

26. Khanna MS, Ikwinder KJPS. Comparative evaluation of bupivacaine plain versus bupivacaine with fentanyl in spinal anaesthesia in geriatric patients. Indian J Anaesth. 2002; 46: 199-203.

27. Singh V, Gupta LK, Singh GP. Comparison among intrathecal fentanyl and butorphanol in combination with bupivacaine for lower limb surgeries. J Anesth Clin Pharmacol. 2006; 22: 371375.

28. Liu SS, Chiu AA, Carpenter RL et al. fentanyl prolong lidocaine spinal anaesthesia without prolonging recovery. Anesth Analg. 1995; 80: 730-734.

29. Varrassi G, Celleno D, Capogna G et al. Ventilatory effects of subarachnoid fentanyl in the elderly. Anaesthesia. 1992; 47: 558-562.

30. Critchley LAH, Short TG, Gin T. Hypotension during subarachnoid anaesthesia: haemodynamic analysis of three treatments. Br J Anaesth. 1994; 72: 151-156. 